\title{
Exploring Stigma by Association among Front-Line Care Providers Serving Sex Workers
}

\section{Explorer la stigmatisation par association chez les fournisseurs de soins de première ligne auprès des travailleurs du sexe}

\author{
एक \\ RACHEL PHILLIPS, PHD \\ Postdoctoral Fellow, Department of Anthropology \& Department of Sociology \\ Centre for Addictions Research of British Columbia \\ University of Victoria \\ Victoria, BC \\ CECILIA BENOIT, PHD \\ Professor, Department of Sociology \\ Scientist, Centre for Addictions Research of British Columbia \\ University of Victoria \\ Victoria, BC
}

\begin{abstract}
Stigma by association, also referred to as "courtesy stigma," involves public disapproval evoked as a consequence of associating with stigmatized persons. While a small number of sociological studies have shown how stigma by association limits the social support and social opportunities available to family members, there is a paucity of research examining this phenomenon among the large network of persons who provide health and social services to stigmatized groups. This paper presents results from a primarily qualitative study of the workplace experiences of a purposive sample of staff from an organization providing services to sex workers. The findings suggest that stigma by association has an impact on staff health because it shapes both the workplace environment as well as staff perceptions of others' support. At the same time, it is evident that some staff, owing to their more advantaged social location, are better able to manage courtesy stigma than others.
\end{abstract}




\section{Résumé}

La stigmatisation par association, aussi appelée «stigmatisation de courtoisie », implique une désapprobation publique évoquée comme conséquence d'une association avec des personnes stigmatisées. Bien qu'un petit nombre d'études sociologiques aient démontré comment la stigmatisation par association limite le soutien social et les possibilités sociales pour les membres d'une famille, il y a peu de recherches qui se penchent sur ce phénomène dans le vaste réseau de personnes qui fournissent des services de santé et sociaux à des groupes stigmatisés. Cet article présente les résultats provenant d'une étude principalement qualitative de l'expérience en milieu de travail d'un échantillon choisi à dessein parmi les membres du personnel d'un organisme qui fournit des services à des travailleurs du sexe. Les résultats font voir que la stigmatisation par association a un impact sur la santé du personnel parce quélle donne forme à l'environnement de travail aussi bien quà la perception, par le personnel, du soutien reçu par les autres. En même temps, il est évident qu'en raison d'une situation sociale plus avantageuse, certains membres du personnel sont plus en mesure que d'autres de faire face à la stigmatisation par courtoisie.

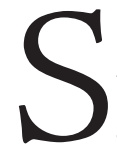

OCIOlOGist ERVING GOFFMAN (I963) DEFINED STIGMA AS A SOCIAL ATTRIBUTE that is discrediting for an individual or group. Stigmas are typically regarded as having a negative impact on self-concept and identity formation (Corrigan et al. 2004; Link and Phelan 2006; Scambler 2009). Expanding on Goffman's social interactionist definition of stigma, Link and Phelan (2001) conceptualize stigma as the co-occurrence of labelling, stereotyping, separating, status loss and discrimination. Their definition, with its focus on structural contexts in addition to relational contexts, has fostered stigma research in two additional areas: (a) the translation of stigmas into broader socio-cultural traditions and institutions, including social welfare policies and (b) the interaction of stigmas with other determinants of health advantage or disadvantage (Link and Phelan 2006; Stuber et al. 2008).

While the bulk of studies have concentrated on the situation of those who experience stigma directly, Goffman (1963: 30) suggested that stigmas also affect those who are closely associated with them - "the problems faced by stigmatized persons spread out in waves of diminishing intensity among those they come in contact with."

There is a small body of work addressing stigma by association or courtesy stigma experienced by family members whose relatives are affected by cognitive disability, HIV/AIDS or psychiatric illness (Corrigan and Miller 2004; Gray 2002; Green 2003; Khamis 2006; Thomas 2006). Studies of parents of children with a disability highlight how stigma by association, much like direct stigma, contributes to inhibited and negative social interactions because parents may perceive judgment and blame with regard to their child's disability or behaviour, or the manner in which they care for their children (Green 2003; Norvilitis et al. 2002; Turner et al. 2007). Stigma by association places strains on the relationship between marked individuals and their family members, ultimately affecting the capacity for social support in this context (Green 2004). 
Corrigan and Miller (2004) note that narratives of blame, shame and contamination give rise to stigma by association. Narratives of blame suggest that the associates of stigmatized persons are culpable or responsible for the negative social implications of the stigma, while narratives of contamination suggest that associates of stigmatized persons are likely to have similar values, attributes or behaviours - "being known by the company we keep" (Kulik et al. 2008; Neuberg et al. 1994; Sigelman et al. 1991).

Existing studies of courtesy stigma among those who provide health and social care support the existence of narratives of blame and contamination. Using a longitudinal design, Snyder and colleagues (1999) found higher rates of turnover among volunteers supporting persons with AIDS compared to other hospice volunteers, which they linked to lower social support for the work in the personal networks of AIDS volunteers. Another study found that physicians who performed abortions faced significant workplace stigma, resulting in reluctance to speak about work publicly and in personal networks, politicization of their workplace purpose and workplace strain (Harris et al. 2011).

In addition to a social-psychological basis for character ascription and ideas of culpability, support for the notion of stigma by association can also be located in sociological studies of "dirty work," which involves things or subjects the public perceives as menial, physically disgusting, socially degrading or morally dubious (Hughes 1962). Dirty work has been associated with a vast range of occupations, including waiting on tables, personal support, garbage collection, abortion support and the sex trade (Harris et al. 2011; Hughes 1962; Twigg et al. 2011). Scholars studying dirty work have investigated, in particular, the various ways that workers interpret and ascribe meaning to their work in the face of public derision (Harris et al. 2011).

While these studies provide a foundation for exploring the concept of stigma by association among workers, very few studies have examined the ways in which the particular social location of workers interacts with stigma in the workplace. This paper undertakes this task, investigating the reasons some staff who engage in morally contested work - specifically, the provision of outreach and related services to sex workers - might be more vulnerable to stigma by association than others.

\section{Research Design and Methods}

The data are drawn from an ethnographic investigation combining participant observation, semi-structured interviews and a short, self-administered questionnaire. A single research site - Peers Victoria Resources Society (PEERS), where services are provided to sex workers was chosen because of the deeply negative stigmas associated with the "prostitute" identity, and because of an existing community-academic collaborative relationship (Hallgrimsdottir et al. 2006). Given the rarity of studies on stigma by association among professional service providers, we chose an exploratory research design that involved repeated, open-ended interviews and participant observation (Guba and Lincoln 1994). Sampling was based on purposive selection, which focused on selective recruitment with the aim of reaching saturation in rela- 
tion to the main research objectives (Glaser and Strauss 1967). Respondents from each of the program areas were included in the study. In total, 12 staff participated in repeated qualitative interviews, and 17 staff completed the supplementary questionnaire. The open-ended interview questions explored work experiences, including job satisfaction, job autonomy, stress and social support, while the self-administered closed-ended measures were used to describe demographic characteristics of the workforce at PEERS and served as a general indicator of workplace health and experiences of stigma. ${ }^{1}$

The questionnaire data were analyzed using SPSS, and the resulting descriptive statistics were used to contextualize the qualitative data with a demographic summary of the sample, to select case comparisons (i.e., persons who had post-secondary education versus persons who did not) and to confirm the qualitative findings (i.e., confirm that respondents experienced occupational devaluation). Analysis of the transcribed qualitative interviews was facilitated by the use of NVivo. The qualitative analysis focused on identifying themes and concepts repeated in the data, case-to-case comparison, and sorting the data according to overriding theoretical questions and research objectives, which focused on the existence and character of stigma by association, as well as variations in experiences of stigma by association. Interpretation and verification were established through discussion with expert informants, select research participants and academic colleagues.

\section{Findings}

\section{Demographic characteristics}

Table 1 summarizes a description of the age, gender, race, household income and family composition of staff who worked at PEERS during the study period. All persons who took part in the interview identified as female or male-to-female transgendered. The median age of participants was 44 years (mean $=42$ ), suggesting that the work is predominantly performed by women in the middle stages of their careers. Workers at PEERS report comparable levels of educational achievement with those in the broader social service community (FCSS 2008, 2009). Despite educational achievement, $77 \%$ of participants indicated their annual household income was equal to, or less than, the census metropolitan area (CMA) average. In addition, it is noteworthy that $35 \%$ of participants were currently lone parents, while only $12.7 \%$ of families in the region are classified as female single-parent families (Statistics Canada 2007). These demographic statistics support the available literature concerning the overrepresentation of female and other marginalized identities (lone parents, in this case) in care work, as well as the limited financial rewards associated with many forms of care work (Benoit and Hallgrimsdottir 2011).

In the course of interviewing and observation, close to two-thirds of the individuals who participated in the research volunteered that they had formerly worked in the sex industry, while approximately one-third of participants noted they had not. Whether or not one had 
a background in the sex industry was of interest in the research as an example of co-occurring stigma, and this formed one aspect of the case comparison in the qualitative analysis. However, we assumed that several dimensions of social experience, including participants' varied experiences of the sex industry, substance abuse, ethnicity and socio-economic status, would likely influence how staff experienced stigma by association.

TABLE 1. Descriptive characteristics of PEERS staff

\begin{tabular}{|l|l|l|}
\hline Variable & PEERS staff & $\begin{array}{l}\text { Victoria (CMA) } \\
\text { (Statistics Canada 2007) }\end{array}$ \\
\hline Median age & 44 & N/A \\
\hline \% Female & 94.1 & 52.3 \\
\hline$\%$ Visible minority & 5.8 & 10.4 \\
\hline \% Aboriginal & 5.8 & 3.4 \\
\hline \% Completed high school & 82.3 & 91.2 \\
\hline \% Completed university degree & 35.2 & 28.3 (persons aged 35-64) \\
\hline Household income (median) & $\$ 38,000$ & $\$ 53,310$ (all households) \\
\hline \% Reported being a female single parent & 35.2 & 12.7 (among census \\
\hline
\end{tabular}

\section{Workplace benefits and constraints}

As other studies of personal service work have found, front-line service workers at the research site felt positive about their opportunity to provide care for those in need, underscoring the notion that for some individuals, service work has significant normative implications (Zelizer 2002):

[The] philosophy, which I think is really important here, is that you accept people where they are ... they have the right to have service, and I think that's quite unusual. $(\mathrm{R} \# 3)$

When asked about the greatest challenges of the job, most participants pointed to a systemic dearth of resources to fill the care gap:

We have to work really hard here, a lot harder in this environment to get help for the clients or to move issues forward. We have to work way harder than other agencies or other causes do .... (R\#6)

Workers at PEERS, like others who perform morally contested work, also described their activities with clients as a social justice activity, adding an additional element of pride to their caregiving roles (Harris et al. 2011): 
I really identified with the idea of using experience as a basis for knowledge, and I liked that we grew hope in our clients and even in the community. Many people came forward against the stereotypes ... . (R\#10)

Patterns in program funding may be one of the key areas where stigmas against clients intersect on a structural level with the workplace experiences of those who serve them (Link and Phelan 2006; Stuber et al. 2008).

You're fully responsible for finding all the money and then to discover that that happens every year ... I'd sort of pictured, going into it, [that] we'll spend a year stabilizing things [financially], but then I realized at the end of year one that all you can really do is reinvent the same year over and over again .... (R\#2)

While short-term and contingent funding is arguably a universal stressor in the nonprofit sector, organizations providing services to stigmatized groups must actively negotiate this stigma in their search for financial resources. In this context, defining the client population and organizational purpose is a task continually fraught with tension:

When talking about strengths and de-criminalization, lots of people are kind of angry, but when I talk about it in terms of women being victims, when I start telling these sad stories, then everyone is like "oh," like there's no animosity. You don't come from a place of victim, you don't get funding. (R\#11)

Depictions of PEERS's clientele as victims of the sex industry was a strategy used to maximize public and funder support for the organization, but many workers felt such framings were in conflict with their personal views and experiences of the sex industry (Hallgrimsdottir et al. 2006):

The perception [that] "oh, so you're saving those victims"... stigmatizes me because then I feel like I'm being put into the same category. (R\#8)

The following section provides a closer look at stigma in the context of day-to-day work and the private sphere.

\section{Contexts of stigma by association}

Table 2 contains a selection of questionnaire responses to measures of stigma operationalized as expectations of devaluation and discrimination (Link 1987). These descriptive statistics provide clear evidence of perceived devaluation associated with working in an organization providing services to sex workers. 
TABLE 2. Expectation of devaluation and discrimination

\begin{tabular}{|c|c|}
\hline Question (adapted from Link 1987) & $\%$ Agree \\
\hline I. Funders are supportive of the work conducted by PEERS Victoria & $29 \%$ \\
\hline 2. I have been treated unfairly by others when they have learned I worked at PEERS Victoria & $35 \%$ \\
\hline 3. I worry that others see me unfavourably because I work at PEERS Victoria & $59 \%$ \\
\hline 4. Most people think less of a person that works at PEERS & $76 \%$ \\
\hline 5. Once they know a person works at PEERS, most people will take their opinions less seriously & $88 \%$ \\
\hline
\end{tabular}

Certain staff noted a variety of contexts, both at home and on the job, where they encountered stigma by association. While most noted that their friends and families accepted the work they performed as important, in many cases, family members were either not comfortable talking about the job or found such conversations wearisome and value laden - "we don't discuss it" (R\#8). Another respondent stated:

You know, my mother has had to struggle with it, too.... I think my mother sometimes feels the stigma from me being in this line of work. (R\#12)

Not being able to talk openly with family and friends about their job for fear of disapproval, or a reluctance to burden others with tensions that surround the work, resulted in a sense of isolation for some staff, a finding that supports other research regarding withdrawal of social support for stigmatized work (Harris et al. 2011; Snyder et al. 1999).

Although my friends were very supportive of my involvement at PEERS, it seemed difficult for them to express interest in what I was doing. ... I seldom said anything to anyone unless they asked, so at times it felt like a lonely venture. (Volunteer \#1)

Staff at PEERS also described both instances of poor treatment as well as fear of discrimination when representing the organization in public contexts, leading to a heightened sense of vigilance regarding representation and discrimination:

I saw the look on her [social worker's] face and I knew that if I gave her the "yes" answer she would see me as less than professional, so I gave her a "not everybody at PEERS has to [have a history] in the sex trade." (R\#3)

I was in a store with my husband, [I] think it was an electronics store, and we were buying something and the guy said to me, "Where do you work?" and I said, "PEERS," and he said, "What is that?" And there was a lot of people at the counter 
and it was the first time that I stopped myself before right out saying prostitute, you know, and I could feel my face flushing bright red and I don't know why that was. (R\#5)

Supporting the notion of contamination narratives as a means of stigma transmission, several staff noted that their involvement with the organization led to questions and assumptions regarding personal background:

Even identifying that I work at PEERS, right, has, you know, [implications].

Depending upon how much the population knows about PEERS already, they will have formed an idea in their head of who I am .... (R\#9)

The above passages also illustrate how stigma by association at PEERS was complicated by the organization's explicit practice of hiring people who had been involved in the sex industry:

All of a sudden I became this token sex worker ... . A lot of people got really [hurt by] that, including me, so we've had to really change the way we think about public education and who's gonna go out and talk about their experience and who's not. $(\mathrm{R} \# 11)$

Public response to the idea of working in an organization that supports sex workers was described as varied and unpredictable and included valourizing, belittling, disdainful or voyeuristic reactions. Anticipating discrimination, some staff described uncertainty about how to share their work with others:

I've become very used to it now after all of these times ... . Whoever invited you to speak is interested, right, but the rest of the room, half of them right away, they are not interested.... It's been tricky to figure out how do you speak to that room. (R\#2)

Some people are really fascinated and just want to hear about it, but it's, you know, it's like a, it's a neat story ... and it can be frustrating. (R\#7)

In addition to feeling pressure to stage their work to generate a favourable response, workers who held formal educational credentials used their training to establish professional authority when faced with stigma by association. One worker described how she believed her professional education offset the discrimination she might otherwise experience as someone with a history in the sex industry: 
The language you use [is important]. If you speak like you may have been university educated, you get results, otherwise you don't. (R\#11)

People are really open when I speak to them on a professional level [but] they ... just don't know how to react to that personal piece. (R\#5)

These examples of impression management support available literature, which argues that workers feel pressure to draw on markers of professionalization as a strategy to distance themselves from the stigmas associated with their clientele (Baines et al. 1992).

Regardless of credentials and experience, participants whose lives were marked by co-occurring stigmas - which in this project were most likely to be due to personal history of one or more of sex industry work, substance use and lack of educational credentials were less likely to speak authoritatively about their ability to neutralize stigmas through various strategies:

I find that I'm not really taken seriously because of the way that I've come from being a client and moved up like that, like I sometimes feel like I don't know if I'm imagining it. (R\#1)

Staff who were able to draw on other sources of prestige and authority could more easily distance themselves from the stigma associated with working at PEERS:

Now for me, it is a bit different because I came from a position of [advantage] and I carry the benefits of that into this job .... (R\#2)

The findings presented here suggest that education, co-occurring stigmas and work experience moderate the effects of stigma by association, but it is likely that a range of other factors - including gender, age, ethnicity, income - also interact with stigma by association when an intersectional model is considered (Hankivsky and Cormier 2009).

\section{Health implications of stigma by association}

[Working at PEERS] took a tremendous toll on my health - [on] my mental health more than anything. $(\mathrm{R} \# 2)$

The questionnaire findings support the descriptions provided by PEERS staff of the health consequences of stigma by association. A significant minority of staff (41.2\%) reported taking a leave of absence for health reasons while at PEERS, and experiencing five or more days of sickness-related absence (29.0\%) in the last six months (see Table 3). 
TABLE 3. Health indicators

\begin{tabular}{|l|l|}
\hline Measure & PEERS Staff \\
\hline \% Report work to be "quite a bit" or "extremely" stressful & 64.7 \\
\hline \% Report health-related leave of absence & 41.2 \\
\hline \% Report "five or more sick days" in last six months & 29.0 \\
\hline Mean emotional exhaustion 27 or greater = high & 26.7 \\
\hline Mean personal accomplishment 39 or greater = low & 41.7 \\
\hline Mean depersonalization 7-12 = moderate & 6.9 \\
\hline
\end{tabular}

According to the results of the Maslach Burnout Inventory, workers at PEERS demonstrated, on average, high levels of emotional exhaustion and a low sense of personal accomplishment, a finding that fits with respondents' descriptions of the job as being mired in systemic issues such as unstable and insufficient funding and uneven public support (Maslach and Jackson 1981). As a point of comparison, staff at PEERS reported higher mean emotional exhaustion and lower mean personal accomplishment than sex workers and healthcare workers in Denmark (Vanwesenbeeck 2005).

\section{Discussion and Conclusion}

The findings presented above indicate that stigma by association is a discernible feature of the everyday reality of PEERS staff (Phillips et al. 2012). They described inconsistent social support from family and friends regarding their work activities, as well as feelings of being treated poorly by professionals in other service organizations and by the public at large. While some staff, armed with a strong belief in their mission and service philosophy, managed to develop strategies to deal with others' misinformation and stereotypes, the high turnover of PEERS staff and their reflections on the advantages of employment in another line of work suggest that stigma by association does take a toll over time. At the same time, they articulated varying levels of concern about, and resiliency to, the negative implications of stigma. Those with higher education showed the most confidence in advancing counter-narratives in the face of discrimination against the work they performed, whereas staff who had previously been in the sex industry or had limited education or work experience were more likely to describe experiences of courtesy stigma as more damaging.

Assessing the relative impact of direct and associative stigmas vis-à-vis other determinants of health (which interact with and transmute stigmas) is a complex issue and one that cannot be reconciled here given the small, single sample. Nevertheless, the insights of scholars who highlight the interconnectedness of various axes of marginalization, as well as the interaction between social determinants of health, are useful in this context (Link and Phelan 2001, 2006; Scambler 2009). Link's (1987) research on the expectations of devaluation and discrimination draws attention to the role of stigma (and by extension, stigma by association) in activating a 
range of secondary outcomes such as withdrawal from social and economic contexts. Viewed from this angle, stigma by association may be more pivotal to the organizational culture of PEERS than it would appear on the surface. The combination of perceptions of others' limited and conditional support for their work, and the stresses described in relation to acquiring and maintaining funding, likely played a role in the low sense of accomplishment reported by PEERS staff. Furthermore, strained social relations between PEERS staff and other allied service organizations curtailed opportunities for successful collaborations that might have improved client support capacity. Stigma by association is thus a sometimes subtle, yet farreaching, workplace stressor that potentially permeates many aspects of workplace activity and worker health.

The available research suggests that unhealthy working conditions and high turnover among service providers are transmitted to service recipients through various suboptimal service delivery practices (FCSS 2008; Yoo and Brooks 2005). Thus, an additional implication of the findings, and an area for further research, concerns how stigma by association affects service capacity (Green 2004).

This study is not without important limitations. Foremost, the small, single-site sample limited the investigation of the factors that intersect with stigma by association. In addition to a need for research with a more diverse and larger sample, comparative research on workers serving more and less stigmatized populations, and among workers who experience different levels of structural disadvantage and varying co-occurring stigma configurations, is recommended. If supported by further research, the findings presented here could have long-range implications for various professions across both the health and social service sectors.

Despite their exploratory nature, the findings of this research support a number of policy and program recommendations. First, echoing others who have suggested that health and social service sites are primary locations for stigma remediation, this research suggests that it is important to educate staff about stigma, but also to invest in employee wellness strategies that take into account how workers may be co-located with their clients in processes of social marginalization (Wieloch 2002). It is also important to consider a collaborative, intersectoral and coalitional approach that focuses on developing partnerships between groups of persons whose health is affected by stigma in various ways. An upstream approach to stigma is likely to have a greater impact on public awareness and public policy than approaches that treat stigmas as disconnected phenomena. This is because stigmas are inevitably relational and are thus not the property of stigmatized groups alone. Such coalitional approaches, to the extent that they foster diversity and more nuanced understandings of social location, help to overcome the tendency for essentialist discourse to emerge regarding stigmatized identities, while also effectively addressing the complex interconnections among processes of social and economic marginalization.

Correspondence may be directed to: Dr. Rachel Phillips, Postdoctoral Fellow, Department of Anthropology \& Department of Sociology, Centre for Addictions Research of BC, University of Victoria, P.O. Box 1700 Stn. CSC, Victoria, BC V8W 2Y2; e-mail: rachelph@uvic.ca. 
NOTE

1. Measures of workplace health included the Beck Depression Inventory (Beck et al. 1979), the Job Content Questionnaire (Karasek et al. 1998) and the Maslach Burnout Inventory (Maslach et al. 1996). Findings from the Maslach Burnout Inventory, which measures three dimensions of burnout - emotional exhaustion, depersonalization and sense of personal accomplishment - are reported in this paper.

\section{REFERENCES}

Baines, C.T., P.M. Evans and S.M. Neysmith. 1992. “Confronting Women's Caring: Challenges for Practice and Policy." Affilia 7(1): 21-44.

Beck, A., A. Rush, B. Shaw and D. Emery. 1979. Cognitive Therapy of Depression. New York: Guilford Press.

Benoit, C. and H. Hallgrimsdottir, eds. 2011. Valuing Care Work: Comparative Perspectives. Toronto: University of Toronto Press.

Corrigan, P., F. Markowitz and A. Watson. 2004. "Structural Levels of Mental Illness Stigma and Discrimination." Schizophrenia Bulletin 30(3): 481-91.

Corrigan, P. and F.E. Miller. 2004. "Shame, Blame and Contamination: A Review of the Impact of Mental Illness Stigma on Family Members." Journal of Mental Health 13: 537-48.

Federation of Community Social Service Strategic Initiatives Fund (FCSS). 2008."Factsheet 1.3: Recruitment and Retention Initiative. The Cost of Worker Turnover." Victoria, BC: Author.

Federation of Community Social Service Strategic Initiatives Fund (FCSS). 2009.“Factsheet 1.7: Recruitment and Retention Initiative. Joining, Staying and Leaving: Factors That Influence Labour Movement in the Social Services Workforce." Victoria, BC: Author.

Glaser, B. and A. Strauss. 1967. The Discovery of Grounded Theory: Strategies for Qualitative Research. Chicago: Aldine.

Goffman, E. 1963. Stigma: Notes on the Management of Spoiled Identity. New Jersey: Prentice-Hall.

Gray, D.E. 2002.“'Everybody Just Freezes. Everybody Is Just Embarrassed': Felt and Enacted Stigma among Parents of Children with High-Functioning Autism." Sociology of Health and Illness 24(6): 734-39.

Green, S.E. 2003."What Do You Mean 'What's Wrong with Her': Stigma and the Lives of Families of Children with Disabilities." Social Science and Medicine 57: 1361-74.

Green, S.E. 2004."The Impact of Stigma on Maternal Attitudes toward Placement of Children with Disabilities in Residential Care Facilities." Social Science and Medicine 59: 799-812.

Guba, E. and Y. Lincoln. 1994. “Competing Paradigms in Qualitative Research." In N. Denzin and Y. Lincoln, eds., Handbook of Qualitative Research. Thousand Oaks, CA: Sage.

Hallgrimsdottir, H., R. Phillips and C. Benoit. 2006."Fallen Women and Rescued Girls: Social Stigmas and Media Narratives of the Sex Industry in Victoria, BC 1980-2005." Canadian Review of Sociology and Anthropology 43: $265-80$.

Hankivsky, O. and R. Cormier. 2009. Intersectionality: Moving Women's Health Research and Policy Forward. Vancouver: Women's Health Research Network.

Harris, L., M. Debbink, L. Martin and J. Hassinger. 2011. "Dynamics of Stigma in Abortion Work: Findings from a Pilot Study of the Providers Share Workshop." Social Science and Medicine 73(7): 1062-70.

Hughes, E. 1962 (Summer). “Good People and Dirty Work.” Social Problems 10(1): 3-11.

Karasek, R., C. Brisson, N. Kawakami, I. Houtman, P. Bongers and B. Amick. 1998. “The Job Content Questionnaire (JCQ): An Instrument for Internationally Comparative Assessments of Psychosocial Job Characteristics." Journal of Occupational Health Psychology 3(4): 322-55.

Khamis, V. 2006. "Psychological Distress among Parents of Children with Mental Retardation in United Arab Emirates." Social Science and Medicine 64: 850-57. 


\section{Exploring Stigma by Association among Front-Line Care Providers Serving Sex Workers}

Kulik, C., H. Bainbridge and C. Cregan. 2008. "Known by the Company We Keep: Stigma by Association Effects in the Workplace." Academy of Management Review 33: 231-51.

Link, B. 1987. “Understanding Labeling Effects in the Area of Mental Disorders: An Assessment of the Effects of Expectations of Rejection." American Sociological Review 52(1): 96-112.

Link, B. and J. Phelan. 2001. “Conceptualizing Stigma." Annual Review of Sociology 27: 363-85.

Link, B. and J. Phelan. 2006. “Stigma and Its Public Health Implications." Lancet (367): 528-29.

Maslach, C. and S.E. Jackson. 1981.“"The Measurement and Experience of Burnout.” Journal of Occupational Behaviour 2: 99-113.

Maslach, C., S.E. Jackson and M.P. Leiter. 1996. Maslach Burnout Inventory Manual (3rd ed.). Palo Alto, CA: Consulting Psychologists Press.

Neuberg, S., D. Smith, J. Hoffman and F.J. Russell. 1994. “When We Observe Stigmatized and 'Normal' Individuals Interacting: Stigma by Association." Personality and Social Psychology Bulletin 20: 196-209.

Norvilitis, J.M., M. Scime and J.S. Lee. 2002."Courtesy Stigma in Mothers of Children with Attention-Deficit/ Hyperactivity Disorder: A Preliminary Investigation." Journal of Attention Disorders 6(2): 61-68.

Phillips, R., C. Benoit, K. Vallance and H. Hallgrimsdottir. 2012.“Courtesy Stigma: A Hidden Health Concern Among Frontline Service Providers to Sex Workers". Sociology of Health and Illness 34, 681-696.

Scambler, G. 2009. "Health-Related Stigma." Sociology of Health and Illness 31(3): 441-55.

Sigelman, C.K., J.L. Howell, D.P. Cornell, J.D. Cutwright and J.C. Dewey. 1991. “Courtesy Stigma: The Social Implications of Associating with a Gay Person." Journal of Social Psychology 131(1): 45-56.

Snyder, M., A.M. Omoto and A.L. Crain. 1999.“Punished for Their Good Deeds: Stigmatization of AIDS Volunteers." American Behavioral Scientist 42(7): 1175-92.

Statistics Canada. 2007. Victoria, British Columbia (Code 935) (table). 2006 Community Profiles. 2006 Census. Statistics Canada Catalogue no. 92-591-XWE. Ottawa: Author. Released March 13, 2007. Retrieved June 22, 2013. <http://www12.statcan.ca/census-recensement/2006/dp-pd/prof/92-591/index.cfm?Lang=E > .

Stuber, J., I. Meyer and B. Link. 2008. "Stigma, Prejudice, Discrimination and Health." Social Science and Medicine 67(3): 351-57.

Thomas, F. 2006. “Stigma, Fatigue and Social Breakdown: Exploring the Impacts of HIV/AIDS on Patient and Carer Well-being in the Caprivi Region, Namibia." Social Science and Medicine 63: 3174-87.

Turner, J., B. Biesecker, J. Leib, L. Biesecker and K. Peters. 2007. "Parenting Children with Proteus Syndrome: Experiences with, and Adaptation to, Courtesy Stigma." American Journal of Medical Genetics 143A(18): 2089-97.

Twigg, J., C. Wolkowitz, R. Cohen and S. Nettleton. 2011. “Conceptualising Body Work in Health and Social Care." Sociology of Health and Illness 33(2): 171-88.

Vanwesenbeeck, I. 2005. "Burnout among Female Indoor Sex Workers." Archives of Sexual Behaviour 34(6): 627-39.

Wieloch, N. 2002. "Collective Mobilization and Identity from the Underground: The Deployment of 'Oppositional Capital' in the Harm Reduction Movement." Sociological Quarterly 43(1): 45-72.

Yoo, J. and D. Brooks. 2005.“The Role of Organizational Variables in Predicting Service Effectiveness: An Analysis of a Multilevel Model." Research on Social Work Practice 15: 267-77.

Zelizer, V. 2002."How Care Counts." Contemporary Sociology 31: 115-19. 